387095

DPSTPH-776-A-2

\title{
PROCESS HAZARDS REVIEW OF THE 904-A TRENCH (U)
}

by

Westinghouse Savannah River Co.

Savannah River Site

Aiken, South Carolina 29808

This paper was prepared in connection with work done under Contract No. DE-AC09-89SR18035 with the U.S. Department of Energy. By acceptance of this paper, the publisher and/or recipient acknowledges the U.S. Government's right to retain a nonexclusive, royalty-free license in and to any copyright covering this paper, along with the right to reproduce and to authorize others to reproduce all or part of the copyrighted paper. 


\section{DISTRIBUTION}

DPSTPH - 77 6-A-2

PROCESS HAZARDS REVIEW OF THE 904-A TRENCH

J. T. Lowe

D. D. Felak

C. W. Smith, Jr.

F. Beranek

T. L. Capeletti

R. R. Fleming

E. W. Holtzscheiter

N. M. Wolfe

P. H. Stevens

D. C. Guyton

D. L. Gunnels

R. M. McManus

H. P. Gibson

T. R. Sloan

D. E. Hiland

J. W. Swain

D. E. Snyder

B. F. Fowler

B. B. Looney

J. A. Lown

A. B. Osteen

H. K. Raines

J. E. Young

SRL Records (4) 


\section{PROCESS HAZARDS REVIEW}

\section{OF THE}

\section{4-A TRENCH}

July 21,1988

By: Process Hazards Review Committee

D. E. Snyder, Chairman

B. F. Fowler

B. B. Looney

J. A. Lown

A. B. Osteen

H. K. Raines

J. E. Young

Prepared by: $\frac{\text { CEAtender, Chairman }}{\text { D. E. Snyder }}$

TNX Operations Division

Approved by:

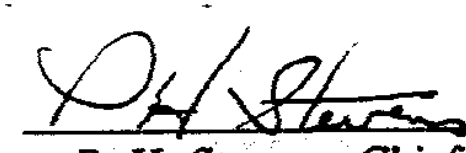

P. H. Stevens, Chief Supervisor

Laboratory Services Division

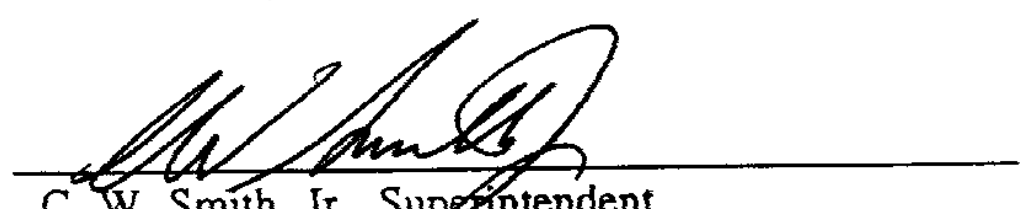

C. W. Smith, Jr., Superintendent

Laboratory Services Division

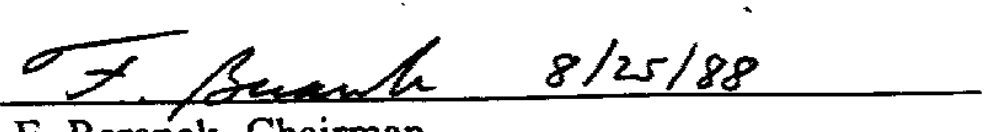

'F. Beranek, Chairman

Process Hazards Management Committee 


\section{CONTENTS}

A. Introduction

1. General Description of Process

2. Scope of Review

3. Reason for Process Hazards Review

4. Summary of Recommendations

5. Hazards Classification

6. Process Hazards Review Committee

B. Process Review

1. Process Description

2. Background

3. Alterations

4. Required Review Topics

5. Review Methodology

C. Findings

1. General Comments

2. Compliance with Procedures

3. Work Practices

4. Facility Maintenance

5. Applicability to Other Safety and Quality Programs

D. Recommendations

Appendix A - What If List 


\section{PROCESS HAZARDS REVIEW \\ 904-A TRENCH}

\section{A. NTRODUCTION}

\section{General Description of Process}

The 904-A trench is an enclosed underground concrete containment for high level and low level radioactive waste lines between the main Laboratory Building 773-A and waste storage and shipping Building 776-A. The waste generated in laboratories and other facilities in 773-A flows by gravity into the high level and low level drain lines, which proceed from 773-A to 776-A through the 904-A trench. The trench ends at 776-2A, where the underground waste handling tanks for both high level and low level liquids are located.

The trench consists of five branches from sections of 773-A: B wing, $C$ wing, D wing, $E$ wing, and $F$ wing. These branches join into a single conduit east of 773-A for conductance to $776-\mathrm{A}$. The trench is about one ft high with varying widths.

The trench serves to contain any leaks originating in the drain lines. The trench is sloped downward toward the Building 776-2A pipe gallery. Any liquid collected from the sump can be pumped automatically to a waste tank and sampled.

The 904-A trench system formerly included a branch originating at $735-\mathrm{A}$ and joining the main trench northeast of 735-A. This branch, however, was disconnected, and all waste from the building is now collected in a separate handling tank located above ground at 735-A.

\section{Scope of Review}

The review of the 904-A trench system included a study of the trench and piping itself, as well as a study of the high level and low level drain lines from the laboratories to the trench. Previously the process hazards review of the Liquid Waste Collection System, 776-A, DPSTPH-776-A-1 included a study of the 776-A complex, as well as criticality considerations for the trench and the high level and low level piping in 773-A.

The present review emphasized an examination of the hazards involved in chemical reactions in the drain lines, misuse of the drains, and criticality.

The following items were examined:

- Process Hazards Review of the Liquid Waste Collection System, DPSTPH-776-A-1.

- Nuclear Criticality Review of the High Level Drain System -- DPST-76-292.

- Improvements in the 904-A Trench System.

- Operating Procedures.

- Unusual Incidents. 
3. Reason for Process Hazards Review

The review of the 904-A trench was conducted to determine if hazards existed that might result in onsite radiation exposure to personnel in excess of annual guides. (Process Hazards onsite criterion \#3).

\section{Summary of Recommendations}

No specific Process Hazard was identified. Several recommendations are made to improve the general safety, operability and reliability of the 904-A trench. A complete listing is found in Section D. Recommendations inciude more complete review of drain usage for chemical compatibility and the addition of shielding in U-loops.

\section{Hazards Classification}

There are no process hazards recommendations as a result of the review of the 904A trench system. The committee believes that future process hazards reviews of the system are not necessary. The periodic review of the 776-A Liquid Waste Collection system should include any interim design changes occurring in the 904-A trench. Reviews of individual facilities within the laboratories should identify hazards involving the liquid waste from the particular facilities.

6. Process Hazards Review Committee

The members of the review committee were:

D. E. Snyder, TNX Operations, Experimental Operations, Chairperson

B. F. Fowler, LSD, Operations Studies

B. B. Looney, Environmental Sciences Division, Geotechnical

J. A. Lown, LSD, Occupational Health Protection

A. B. Osteen, LSD, Area Waste Coordinator

H. K. Raines, LSD, Area Operations

J. E. Young, SRP, Laboratories (formerly SRL, LSD Area Operations Supervisor)

\section{B. PROCESS REVIEW}

\section{Process Description}

The 904-A Trench is an underground box that contains the piping that carries the high level (HL) and low level (LL) radioactive liquid waste from Building 773-A to the tanks at 776-A.

The liquid that enters the piping in the 904 Trench originates in hood or glove box cups and sinks that are located in labs. The liquid from B \& $C$ wings flows down through stainless steel piping, encased with nylobraid hose, into the $\mathrm{HL}$ and $\mathrm{LL}$ headers in C-005 and B-005. The liquid in F wing flows from cells and floor drains into headers, through F-080 and into the 904 Trench piping. Liquid in E wing flows from cells and floor drains, through the $E$ separator pit and into the 
904 Trench piping. Liquid from D wing flows either into the trade waste system or into the LL piping in the 904 Trench.

The trench box is constructed of concrete with a concrete cover that is intended to be watertight. The outer surface of the box is covered with a membrane made of hot asphalt, several layers of fabric and another layer of hot asphalt. The box varies in size depending on the piping and junction of piping inside.

Junction boxes are located at six locations where piping from different wings joins the main trench on its way to $776-A$.

The piping in the trench is stainless steel, all welded joints. There are two (2) 6 in. low level pipes and two (2) 3 -in. high level pipes. The 3 -in. HI piping is increased to a 4-in. pipe after Junction Box D, where 735-A originally entered the system. The lines from 735-A were blanked off when the ultra-low level counting room was installed underground noth of $735-\mathrm{A}$.

The piping was hydrostatically tested in 1986 and is to be tested periodically to determine if there are any leaks.

Monitor points have been installed at all junction boxes. This will make it possible to see and measure any liquid that might be in the 904 Trench.

\section{Background}

The 904-A trench was designed and constructed as part of the original project in the Technical Division Area. Construction was completed and operations began in 1953. The system has been in service since that time. The Building 735 - $A$ branch to the 904-A trench was removed from the system in 1984. The Process Hazards Review of the 776-A Liquid Waste collection System included a recommendation to restore the high level and low level radioactive waste drains. Through Project $S$ 2598 recent improvements to restore/upgrade the system have been made.

The trench system is operated by the Area Services and Operations Group of the Laboratory Services Division. The SRL Procedures Manual contains procedures and guidelines for disposal of liquid wastes in laboratory drains. There are also procedures for the operation of the bigh level drain flushing system. The 904-A trench system normally does not require attendance of an operator.

\section{Alterations}

- Trench from F-wing was added 20 years ago. Approximately $425 \mathrm{ft}$. of trench was added with four (4) 3-in. lines, HL normal and spare and LL normal.and spare.

- In 1981 two (2) 2 -in. HLD headers running down each side of B-005 and C-005 were replaced with one (1) 2-1/2-in. 304L schedule 40 stainless steel header down the middle of the shielded area. The wo old lines were abandoned in place.

- All welds on the $\mathrm{HL}$ and $\mathrm{LL}$ drain lines in trench were radiographed when originally installed. 
Project S-2598

- The 2-1/2-jn. $304 \mathrm{~L}$ schedule 40 high level stainless steel header was removed and a new 3-in. $316 \mathrm{~L}$ schedule 80 stainless steel header was installed. The two original headers down each side of B-005 and C-005 were removed.

- The $304 \mathrm{~L}$ schedule $40 \mathrm{HL}$ drain lines from the labs to the headers in B-005 and C.005 were replaced with $316 \mathrm{~L}$ schedule 80 stainless steel.

- The $304 \mathrm{~L}$ schedule $40 \mathrm{HL}$ drain lines and valves from the headers to the point the lines enter the B-002 and C-002 trench were replaced with $316 \mathrm{~L}$ schedule 80 stainless steel.

- All piping in $B-002$ and $C-002$ (304L) were replaced up to the U-loops with $316 \mathrm{~L}$ stainless steel.

- Block and bleed valves were added in F-080, B-001, B-002, C-001 and C-002 to hydrostatically test lines in trench.

- HLD U-loops (304L) in B-002, C-002, and F pit were replaced with $316 \mathrm{~L}$ stainless steel $U$-loops.

- A LLD U-loop (304L) in F pit was replaced with a 316L U-loop.

- A LLD U-loop (304L) in B-002 was replaced with a glass U-loop. There is a constant problem with this U-loop becoming clogged with solids and sediment.

- The drain lines from the HLD cup sinks are a standardized design and drop straight down to the service floor instead of having bends.

- A standard location for cup sinks within hoods and gloveboxes was provided.

- Secondary containment was grovided from each hood and glovebox to the header in the service floor. Secondary containment will be SST tubing in the labs and nylobraid hose in the service floor.

- A monel screen was installed in the cup sinks to prevent solids from entering the drains.

- A trough bas been added below the HLD header in B-005 and C-005 and runs to the first valve where the piping exits from the building into the trench. Liquid detectors have been installed in the trough to detect any leaks. If a leak exists, the liquid drains down the trough to a closed valve. If liquid is detected, the valve will be opened and the liquid will be collected in a bucket.

- Where possible, hoods and gloveboxes are being relocated over the shielded area of the service floos. All hoods have been relocated and approximately $2-6$ gloveboxes will remain outside of the shielded area.

- Exhaust for the trench was installed at 776-A to provide a positive air sweep through the trench.

- Monitor ports were installed in ten locations. This requires that a hole be drilled (12 in. diameter) in the top of the trench slab at each location. A dike, 
weit and liquid level detector are being placed in the trench at each location to detect liquid and to help determine the location of leaks.

Project S-3219

- Two 25-ft lengths of 2-in-diameter $316 \mathrm{~L}$ schedule 80 LLD line were added to allow the discharge of solutions containing depleted uranium from $D$-Wing. The pipe was jacketed with 4 -in. $304 \mathrm{~L}$ schedule 10 pipe and included liquid detectors in the bottom of the jacket. The line was run from the lab to the existing trench where the lines were tied into existing pipe. Installation required removal of 2 or 3 trench covers. After work is completed, Volclay will be used to reseal the trench.

\section{General}

- Recommendation has been made in DPSTP-2.10 that caps be placed on HLD cup sinks in gloveboxes.

- Hydrostatic testing facilities will be installed in $C$ and $E$ pits under separate funding. This should be complete by mid-1988.

- Approximately $50 \mathrm{ft}$ of $\mathrm{HL}$ and $\mathrm{LL}$ drain lines from 735-A were removed for the installation of the Underground Counting Facility. The trench was removed to within $50 \mathrm{ft}$ of junction box $\mathrm{D}$. The ends of the lines in the trench were covered with a jacket and pipe cap and the end of the trench was enclosed with concrete.

- When an area is excavated, the trench is being sealed with the Volclay Waterproofing System instead of tar..

- A leak in the trench in C-courtyard has been sealed with the Volclay system.

- HLD piping in $E$ and $C$ auxiliary pits will be replaced with $316 \mathrm{~L}$ schedule 80 stainless steel at a later date.

- Block and bleed valves will be added to E-Separator Pit and C-Auxiliary Pit.

- A HLD and LLD U-loop in C auxiliary pit will be replaced with $316 L$ U-loops in the future.

- Double block and bleed valves were added upstream of HLD U-boops so hydrostatic tests of the lines can be performed.

- Block and bleed valves were added downstream of the LLD U-loops.--Block and bleed valves were already in place upstream of the U-loops.

- Leaking drum traps in LLD are being replaced.

- LLD piping from the sinks to the stub ups in the service strip of each lab are being replaced with $316 \mathrm{~L}$ schedule 40 stainless steel pipe. 
- Service floor LLD piping will be replaced if corrosion is found, otherwise it will remain as is. No LLD lines have been replaced to date.

- All U-loops have been removed, cleaned, inspected and reinstalled. Biological growth has been found in the LLD U-loops and the piping adjacent to the Uloops.

- HLD lines in $E$ and $F$ wings will not be replaced. There is no evidence of a need to replace the lines.

- Some HLD piping in $F$ auxiliary pit has been replaced with $316 \mathrm{~L}$ schedule 80 stainless steel.

- New pipe specification has been written (P252) for HL drain piping.

- Vent at end of HLD lines that was used when P-traps were in the HLD lines underneath the cup sinks has been removed.

\section{Required Review Topics}

a. Changes of design that were examined as part of the review included elimination of the high level $U-l o o p$ in $E$ wing, elimination of the $735-\mathrm{A}$ branch trench, replacement of high level drain headers, installation of monitor ports and dikes in the trench, and addition of a low level drain line from $D$ wing. These were reviewed to determine if any effects on overall safety were created.

b. Incident Report Review

All available files were "searched for incident reports involving the waste lines or the 904-A trench. Only one documented incident, reported January 26 , 1972 as DPST-72-210, was found as a result of this search. The incident involved the release of radioactive wash wates into the 904-A trench as well as the ground, Tin's Branch, and the SRL seepage basins. Of the six recommendations in the report, all were determined to be completed.

c. Relief Protection Review

There are no relief protection devices in the 904-A trench system and none are required.

d. Previous Safety Analysis Reports

There are no safety analysis reports of the 904-A trench system.

e. Previous Process Hazards Review

There is no previous process hazards review of the 904-A trench system.

f. Modes of Operation

The modes of operation teviewed for the 904-A trench systen included both normal shutdown and emergency. These were included as part of the review checklist items. 
g. Quality Assurance Requirements

A Quality Assurance assessment is required for any replacement of high level or low level drain lines or components or the replacement or alteration of the trench.

\section{Review Methodalogy}

The "What If" method was used to analyze the 904-A trench system. "What If" questions were used against a review checklist developed by the committee. The questions, consequences, and recommendations are listed in Appendix A.

\section{FINDINGS}

\section{General Comments}

The 904-A Trench Process Hazards Review Committeee evaluated the potential for exposures or releases at the various entry points into the facility. Several scenarios including normal operation, shutdown, emergency operation and process upset were postulated and evaluated for each of the following locations/systems: pipelines, traps, U-Loops, separator pits, concrete trench, strainers, 776-A junction, exhaust system, and the flushing system. The process upset scenarios included: chemical reactions (fire, explosion, heat generation, gas generation), criticality, violation of procedures, line pluggage, and physical damage (heavy equipment, extreme weather). Existing documentation of facility operation (procedures, unusual incident reports, maintenance and training records) and interviews with individuals familiar with the facility were all considered in the process hazards review. Several recommendtions resulted from the review. These recommendations will help assure continued safe operation of the radioactive waste drain system.

The committee luemuses sus pusintial for chemical reaction as the event with the highest probability for causing an exposure or release of material. Modification of the SRL waste handling procedures to include additional controls to assure compatibility of materials in the drains was recommended. Also; a task team to generate a screening method based on reactivity, corrosivity, etc. to assist in implementing the modified procedure was recommended. Several recommendations related to the operation of the exhaust system were made by the committee.

The facility has operated successfully since 1953. One unusual incident that resulted in a release of radioactive washwater to the rrench and ground was documented (DPST-72-210). All of the recommendations resulting from this incident have been implemented. The committee determined that the liklihood of a nuclear incident is extremely low. Recent improvements to the 904-A Trench System (e.g., monitor ports), along with some of the review recommendations (e.g." additional shielding), will reduce this potential further.

\section{Comoliance with Procedures}

Operating procedures for discharging waste to the high and low level lines contained in the 904-A trench are outlined in the SRL Waste Handling Procedure DPSTP $2.10(4 / 87)$, Laboratory personnel are required to review this DPSTP as 
part of the orientation process in the Savannah River Laboratory. Analysis of the discarded waste indicated adherence to these guides.

The operating procedure for the high level flush tanks (DPSTOM 32, 3.04) is no longer applicable and should be updated. Four procedures or other procedure modifications were recommended as a result of the process hazards review exhaust system operation, monitor port operation, pressure test procedure, and waste handling procedure (modification).

\section{Work Practices}

Additions to the high and low level drain lines are made in the laboratories via low level sinks and high level cup sinks by trained Technical Assistants. These Technical Assistants receive training on disposal methods for materials with which they are working from the first line supervisor or researcher to whom they are assigned.

The high level flush tanks are operated by 14 operators qualified through a thorough training program. Two operators on each of 4 shifts and 6 operators on days are assigned to the Building Operations function of the Technical Division Area, which includes 773-A, 904-A trench and the Waste Handling Facility, 776A.

There are no procedures as yet for the trench monitor ports, which were recently installed as part of the S-2598 High and Low Level Radioactive Waste Drains Project. Because this project is not complete, these monitor ports have not been turned over to the operating group.

\section{Facility Maintenance}

The 904-A trench has been in service since 1953. All lines in the trench have been hydrostatically tested within the last two years. Testing will continue every three yearrs.

\section{Applicability to Other Safety and Quality Programs}

The SRL Waste Handling Procedures (DPSTP-2.10), along with the process hazards and criticality reviews of related facilities, help to assure the safety and quality of the 904-A Trench System. A quality assurance assessment will be required for any replacement of high or low level drain lines, or for any engineered alteration to the 904-A trench system. Since the 904-A Trench System is essentially a passive containment structure, the several procedures (associated with the general operation of the drain system and with building 776-A) and recommendations listed above will assure continued high quality safe operation. No other quality assurance or safety programs are recommended.

\section{RECOMMENDATIONS}

The following recommendations are made to improve the general safety of the facility. 
- Add to the General Provisions of the SRL Procedures Manual DPSTP-2.10 (4/87): Coordinate compatibility of chemicals disposed of down the drains. Use the reactivity and/or the corrosivity and the volume of the liquid: If the factors are above a certain number then check with Area Services before disposal.

- Add to the SRL Procedures Manual that materials incompatible with nitric acid must be reviewed before disposing of down the drains.

- A team of 4 or 5 chemists review reaction scenarios and make recommendations to further restrict the possibility of unwanted chemical reactions in the drain system.

- Investigate possibility of installing shielding between legs of U-loops.

- Continue quarterly monitoring (characterization) of discharge stream.

- Install U-loops in E-wing of building 773-A.

- Write a procedure for opening monitor ports and include that ports cannot be opened when trench exhaust is off or when radiation alarm sounds.

- Repair and seal trench as determined necessary by monitor port observation.

- Install signs as far as physically possible along length of trench stating that Area Services must be notified if excavation is done or heavy equipment is used in areas around the trench. Alternate suggestion: provide procedural control.

- Change antomatic flushing system to manual flushing to ensure adequate flushing takes place.

- Write procedure to hydrostatically test lines in trench every three years.

- Revise procedures DPSTOM-33, DPSTP-2.10 and 3.04 .

DPSTOM-33, 2.08

1. Remove 735-A from general description

3. Change Building Operations to Area Operations DPSTOM 32, 3.04

1. On page one change 8 water tanks to 4

2. On page two eliminate reference to brass keys

3. On page 3 change tanks to show 4 instead of 8

4. On page 5 change operation of flushing tanks.

- Install start/stop switch and light for tank exhaust fans on the control panel in 776-A.

- Install neutron monitors in F-080 and E\&C separator pits. (Reference-DPSTPH776-A-1).

- Restore operation of liquid level detectors in F-080 sump.

- Have OHP smear down each side of B-005 and C-005 in addition to the smear that is done down the center of these areas. 
- Add to DeSTP-2.10 the additional criteria stated in Memorandum dated May 20, 1987.

- Write a procedure for exhaust system operation.

- Install conductivity meter upstream of HLD and LLD U-loops to detect standing water.

- Write procedure for operation of U-loops.

- Verify operation of neutron monitors U-loops periodically per written procedure.

- Install trench exhaust failure alarm in 776-A Control Room. 


\section{APPENDIX_A}

What If

Consequence

Recommendation

What if

Consequence

Recommendation

What if

Consequence

Recommendation

What if

Consequence

Recommendation
1. An organic or solvent is disposed of down the drain?

Flashing could occur in the pipe and any gas given off would be removed by exhaust system.

Any fire inside pipe caused by a chemical reaction would not sustain itself.

Need more control on chemical disposal. Form a team of chemists to review chemical reaction scenarios. Use results of team to revise procedures to further restrict possibility of undesirable chemical reactions. Should investigate use of MSDS and chemical stickers.

Add to procedure DPSTP-2.10 that materials incompatible with nitric acjd the main waste constituent, must be reviewed before disposal.

2. Chemical reaction occursed at a cup sink during disposal of chemicals?

Chemicals could burp back up to the cup sink.

Same as \#1.

3. Flushing system does not work?

Could have accumulation of fissile material in $u$ loops.

Investigate the possibility of Installing shielding between legs of U-loops. (Neutron monitors being installed per DPSTPH-776A-1).

4. Exhaust system for 776A tanks fail?

Exhaust on the HLD lines will provide exhaust of the drain lines from the cup sinks to the $U$. loops. The line to E-wing will be exhausted by the E-wing exhaust and pull fumes from the tanks at $776 \mathrm{~A}$ back into the service area. The lines from the U-loops to $776 \mathrm{~A}$ will be in a static condition.

Install U-loops in E-wing. 
What if

Consequence

Recommendation

What if

Consequence

Recommendation

What if

Consequence

Recommendation

What if

Consequence

Recommendation

What if

Consequence

Recommendation
5. HLD line exhaust fails?

Tank exhaust at $776 \mathrm{~A}$ would provide air sweep of the drain lines downstream of the U-loops.

Upstream of the U-loops the fumes in the lines would be pulled into hood and gloveboxes and exhausted through hood exhaust and OGE. The HLD line to E-wing would be exhausted by the tank exhaust.

Install U-loop in E-wing.

6. 776-A tank exhaust and the HLD line exhaust fails?

Air from the tanks at $776 \mathrm{~A}$ could be pulled back into high bay area of E-wing. Toxic fumes will not be detected in the high bay area.

Install U-loop in E-wing HLD line.

7. Normal power and $776 \mathrm{~A}$ diesel generator fails?

$776 \mathrm{~A}$ is evacuated.

None

8. Line in trench breaks?

Majority of liquid would drain down the trench to $776 \mathrm{~A}$ LL pipe gallery and would be pumped to tank C. Slow seepage out of trench at the joints will occur. Liquid level detectors in trench would detect the leak and alarm the $773 \mathrm{~A}$ control room.

None

\section{U-loop leaks?}

Liquid drains to sump in $B, C$, and $F$ wings and is pumped to appropriate place. The separator pits (C and $E$ ) have liquid level alarms:- Liquid is pumped out with a jet line back to HLD.

None 
What if

Consequence

Recommendation

What if

Consequence

Recommendation

What if

Consequence

Recommendation

What if

Consequence

Recommendation

What if

Consequence

Recommendation

What if

Consequence

Recommendation
10. Traps on LLD inside shielded area of service floor leak?

Daily activity in shielded area on service floor may detect leaks. Smears ate done daily down the middle of B-005 and C-005.

Smear down each side of B-005 and C-005

11. Traps on LLD outside of shielded area leak?

LL waste will leak to offices and labs in service floor. Leaks are monitored.

None

12. Maintenance work needs to be done on $\mathrm{HL}$ or $\mathrm{LL}$ drain lines?

No mainenance work is done without a special job plan or WCP.

None

13. Trench exhaust fails?

Air would be pulled through $776 \mathrm{~A}$ or $773 \mathrm{~A}$ exhaust systems.

Install alarm in $776 \mathrm{~A}$ control room that will alert operators if the trench exhaust fails.

14. Trench is pressurized?

There is no place for pressurization to come from.

None

15. Heavy equipment is used in close proximity of trench?

Possibility of cracking the trench or breaking a line.

Install signs as fas as physically possible along length of trench stating that Area Services should be notified before using heavy equipment or excavating; or alternately. provide procedural control. 
What if

Consequence

Recommendation

What if

Consequence

Recommendation

What if

Consequence

Recommendation

What if

Consequence

Recommendations

What if

\section{Consequence}

Recommendation

What if

Consequence

Recommendation
16. Freezing temperatures occur?

Pipe is a mininum of 5 feet below grade and should not freeze at this depth.

None

17. Flooding conditions occur?

Constant in-leakage will drain to 776-A and be pumped to appropriate tank.

None

18. Drain line plugs?

This is a very low probability. Per procedures no solids are to be disposed of down the drains. Monel screens will be placed inside HLD cup sinks to help prevent disposal of solids down the HID.

is is None

19. Strainers plug?

Alarm would indicate to operations that the strainers are plugged and they would be replaced. Neutron monitor would indicate potential criticality problem.

None

20. HEPA Filters on the drain line exhaust plug?

Would be detected by magnehelic gage and the filters would be replaced.

None

21. Flush system for drain lines fails?

Corrosion will be accelerated

None 
What if

Consequence

Recommendation

What if

Consequence

Recommendation

What if

Consequence

Recommendation

What if

Consequence

Recommendation

What if

Consequence

Recommendation

What if
22. HLD U-loop plugs?

HID would back up into $B$ and $C$-wing service floors.

Install conductivity meter upstream of HLD $U$ loops to detect standing water.

23. LLD U-loop plugs?

LLD would back up onto service floors in B, C and $F$ Wings.

Install conductivity meter upstream of LLD Uloops to detect standing water.

24. Hydrofluoric acid is not complexed with aluminum nitrate?

Corrosion of lines will be accelerated. Any leaks will be contained by the jacket from the cup sink to the header or the trough underneath the header.

None

25. Liquids are not allowed to cool before disposal?

Corrosion of lines will be accelerated.

None

26. Suspended solids are not separated prior to disposal into LLD.

Could clog drain. Solids would be detected in samples from tanks at 776A and appropriate action could be taken by Area Services.

Strainers at 776-A remove the larger solids.

None

27. HLD leaks inside the service strip? 
Consequence

Recommendation

What if

Consequence

Recommendation

What if

Consequence

Recommendation

What if

Consequence

Recommendation

What if

Consequence

Recommendation

What if
HLDs are jacketed with stainless steel tubing and the leak would drain to HLD Header.

None

28. HLD heades in B-002, C-002 or C-005 leaks?

The trough under the header will contain the leak. The trough drains to a closed valve. Liquid detectors will alarm in 773-A Control Room.

None

29. HLDs are not washed down after disposal of chemical in a cup sink?

Radiation in the lines increases. Corrosion rate is accelerated.

None.

30. Fissile material is dumped without approval?

Neutron monitors at the U-loops and $776 \mathrm{~A}$ would detect fissile material. Each lab has controls on the amount of fissile material allowed in lab. To have a criticality, a large amount of fissile material would have to collect in the U-loops or strainers. This possibility is very remote.

None

31. Fissile material and organics are disposed of at the same time in the HLD?

Organics would form layer and attract $239 \mathrm{PU}$. Could cause a flammability problem in $F$ evaporator. Each tank is sampled for $\%$ oil before F-area accepts shipment.

None

32. HL waste is put down LLD? 
Consequence

Recommendation

What if

Consequence

Recommendation

What if

Consequence

Recommendation

What if

Consequence

Recommendation

What if

Consequence

Recommendation

What if

Consequence

Recommendation
Does not affect trench. AS \& $O$ would have $H L$ waste in their LL tank. After disposal of waste, an attempt could be made to decon the $\mathrm{LL}$ tank so it could be used for $\mathrm{LL}$ waste again.

None

33. Hazardous materials are put down LLD?

Would have no affect on the trench. The material could be corrosive, ignitable or toxic but it would be diluted when it gets to the tanks at $776 \mathrm{~A}$.

None

34. Inspection or testing of the lines needs to be done?

No work on the HL or $\mathrm{LL}$ drains is done without a job plan and WCP.

None.

35. Materials of construction of the urench fail (concrete, tar covering)?

Any cracks in the concrete trench or failure of the tar seal will result in more inleakage of percolating rainwater and a slightly higher potential for liquids in the trench leaking out and contaminating the surrounding soil in the event of a pipe failure.

Repair and seal trench as determined necessary by monitor port observations.

36. LL waste from trench is drained to HL tank instead of LL overflows?

Would be processed as if it were HL waste.

None

37. Steam is lost during a transfer between tanks at $776 \mathrm{~A}$ ?

Transfer would be stopped.

None 
What if

Consequence

Recommendation

What if

Consequence

Recommendation

What if

Consequence

Recommendation

What if

Consequence

Recommendation

What if

Consequence

Recommendation

What if

Consequence

Recommendation

What if
38. Sump at $776 \mathrm{~A}$ overflows?

Floor would be contaminated and effort would be made to decon the floor.

None

39. Building sumps in $773 \mathrm{~A}$ overflow?

Same as \#38.

None

40. Flushing tanks in 773-A fail and do not stop flushing?

Would not affect trench. Could possibly fill up tanks at $776 \mathrm{~A}$.

None

41. Sight glass for flushing tanks breaks?

Would lose fush water and lines would not get flushed. Could accelerate corrosion.

None

42. Float switches in flush tanks do not operate properly?

Could eliminate fushing or could cause continuous flushing

Change automatic flushing system to manual flushing.

43. Procedures for dumping fissile materials are violated?

Drain lines will not support a criticality. Neutron monitors in U-loops will pick up violation.

Write procedure for operation of U-loops.

44. Neutron monitors at U-loops fail? 
Consequence

Recommandation
Because of restrictions on fissile materials in labs it would take a long time for enough material to accumulate to cause a criticality. If the material did accumulate, there would not be any waming for a criticality.

Monitors should be checked periodically per procedure referenced in $\# 43$. 